\title{
EFFECTS OF EPISTEMIC PREPARATIVE ACTIVITIES ON STUDENTS' UNDERSTANDING IN A FLIPPED CLASSROOM
}

\author{
Wakako Fushikida ${ }^{1}$, Hiroki Oura ${ }^{2}$ and Ryo Yoshikawa ${ }^{3}$ \\ ${ }^{I}$ University Education Center, Tokyo Metropolitan University, Japan \\ ${ }^{2}$ Center for Innovative Teaching and Learning, Tokyo Institute of Technology, Japan \\ ${ }^{3}$ Faculty of Information and Media Studies, Nagoya Bunri University, Japan
}

\begin{abstract}
This study aims to evaluate cognitive learning outcomes using a comprehension test in a flipped classroom designed to integrate both acquisition and utilization of new knowledge. In this study, as epistemic preparative activities (EPA), we proposed authentic adventure games that are relevant to the learning contents of lecture videos and face-to-face activities, which can encourage students to understand and apply knowledge. Furthermore, we compared students' scores in the comprehension tests between an individual EPA group and a collaborative EPA group, in order to determine which EPA style has a greater advantage in a flipped classroom model. These findings indicate that the collaborative EPA group tended to perceive greater understanding of the material. We assumed that collaborative EPA effectively encourages students in knowledge acquisition and construction.
\end{abstract}

\section{KEYWORDS}

Flipped Classroom, Epistemic Cognition, Statistical Education

\section{INTRODUCTION}

\subsection{Review of Previous Studies}

The flipped classroom model was invented in the United States around the year 2000, and spread to primary and secondary education as a part of teachers' grassroots efforts within the country. It was rapidly introduced in Japan in the 2010s as a new effective teaching method. Flipped classroom is an instructional approach that employs lecture videos and quizzes as homework assignments before class. Students engage in advanced tasks with individual tutoring or interactive and collaborative activities during class. According to Bergmann and Sams (2014), the shift in direct instruction from traditional lectures to teacher-created videos produces richer and more meaningful experiences for students in face-to-face learning.

Even though flipped classroom is considered an extremely innovative approach, there is a history that has been practically improved through trial and error by the teachers in charge. In the process of development, some previous studies emphasized the necessity to connect the flipped classroom's online learning with face-to-face activities to facilitate leaner knowledge construction and application in higher-order thinking (Strayer, 2012, Kim et al., 2014). However, there are few studies that explore design principles and look objectively at the evaluation of learning outcomes (Bishop \& Verleger, 2013).

\subsection{Perception of the Present Study}

This study aims to evaluate cognitive learning outcomes using a comprehension test in a flipped classroom designed to integrate both acquisition and utilization of new knowledge. Some earlier studies suggested the effectiveness of preparation for future learning (PFL), that engages students in some exploratory activities before conducting lectures and explanation of learning content (Schwartz \& Martin, 2004, Schneider \& Blikstein 2015, Oura et al. 2018). Based on these findings, we incorporated problem-solving activities using 
an adventure game into PFL before students watched lecture videos as online learning. The following research questions were explored: (1) What changes have occurred in students' understanding? (2) What kind of PFL activities are effective for achieving learning outcomes?

Recently, epistemic cognition (EC), which is related to acquisition, understanding, judgement, and application of knowledge, has drawn attention in the context of complicated modern societies. EC involves thoughts about people's behaviors that are concerned with what and how people perceive knowledge, and activation of EC is helpful for effective learning (Greene et al., 2016). In this study, as epistemic preparative activities (EPA), we proposed authentic adventure games that are relevant to the learning contents of lecture videos and face-to-face activities, which can encourage students to understand and apply knowledge. Furthermore, we compared students' scores in the comprehension tests between two EPA groups in order to determine which EPA style has an advantage in a flipped classroom.

\section{METHODS}

We conducted a flipped classroom experiment in an introductory course " $\mathrm{X}$ " of statistical and data analysis during the winter semester of 2018 at Y University in Tokyo. Fig 1. shows the schedule of this practical experiment. First, students played statistical adventure games for about 30-45 minutes, individually or collaboratively, in class as EPA. They read a story which assumes a population with a certain probability distribution, and solved scenario-based problems (such as "Which store has the longest waiting time?") that involved the collection of sample data by choosing a sample size (N=10, 100, or 1000) and interpreting histograms, boxplots, and descriptive statistics (Figure 2).

Prior to the next class, they were required to watch lecture videos uploaded on the dedicated webpage using a personalized login ID and password. The five online videos (of about four and a half minutes each) dealt with basic statistical concepts such as "parameter estimation," "normal distribution," and "histogram." Finally, in class, they collaboratively solved practical statistical problems in smalls group (of about four students each). All students were allowed access to the lecture videos and computation tools, and instructed to share their thinking process with each other during problem solving.

Seventeen undergraduate students participated in the course, including one overseas student, and agreed to our request of experimental cooperation. They included 11 males $(68.8 \%)$ and 5 females $(31.3 \%), 14$ first-year students $(87.5 \%)$ and 2 students of other grades $(12.5 \%)$, and 4 students of humanities $(25.0 \%)$ and 12 students of science $(75.0 \%)$. We divided the 17 students into two groups: 6 students in the individual EPA group, and 11 students in the collaborative EPA group, which included three sub-groups. There were differences between the two groups in terms of activity style; the former engaged in EPA individually, while the latter played the statistical adventure games collaboratively.

We administered pre- (before EPA), middle- (after EPA and watching lecture videos), and post- (after face-to-face collaborative inquiry activities) comprehension tests in order to evaluate students' understanding. A total of sixteen valid responses were obtained, excluding one absentee. The three tests were identical and were designed with regard to the following: "population and sample," "frequency distribution table and histogram," "parameter estimation," and "normal distribution and representative value." They included multiple choice questions, written components, and computational problems, with no use of calculators or spreadsheet software. Each question was scored as $0,0.5$, or 1 by the first author of this paper. The average scores were $10.25(S . D .=1.68)$ in the pre-test, $12.05(S . D .=2.20)$ in the middle-test, and 12.48 $(S . D .=1.74)$ in the post-test on a scale of 1 to 16 .

\begin{tabular}{|c|c|c|c|} 
EPA: Epistemic Preparative Activities \\
individually or collaboratively in class
\end{tabular}

Figure 1. The schedule of the practical experiment 

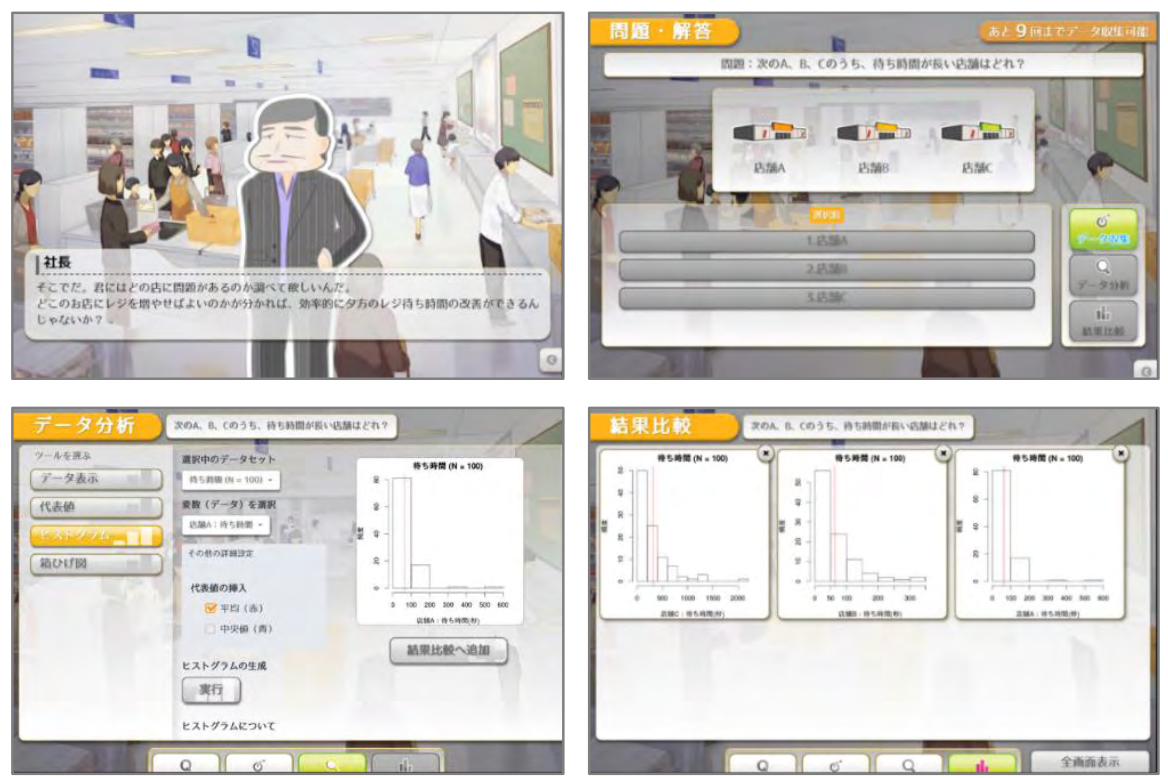

Figure 2. Screenshots of the statistical adventure games

(top left: a story of problem contexts; top right: a scenario-based problem; bottom left: analyzing data tools such as histograms and descriptive statistics; and bottom right: comparing results for answering the problem)

\section{RESULTS AND DISCUSSION}

We analyzed the comprehension test scores using a mixed-design analysis of variance model (also known as a split-plot ANOVA) to reveal the effects of a flipped classroom with EPA on students' understanding. The results in Figure 3 show that there were significant differences between test scores $(F(2,28)=39.22, \mathrm{p}=.00$, $\left.\eta^{2}=.74\right)$. According to a Holm's sequentially rejective Bonferroni test, in the individual EPA group, the post-score was significantly higher than the pre-score $(d=1.35,95 \% C I=.15 \sim 2.56)$, and in the collaborative EPA group, the middle-score $(d=.86,95 \% C I=.00 \sim 1.72)$ and post-score $(d=1.10,95 \% C I=.19 \sim 2.01)$ were significant higher than the pre-score. These findings indicate that the collaborative EPA group tended to perceive greater understanding of the material.

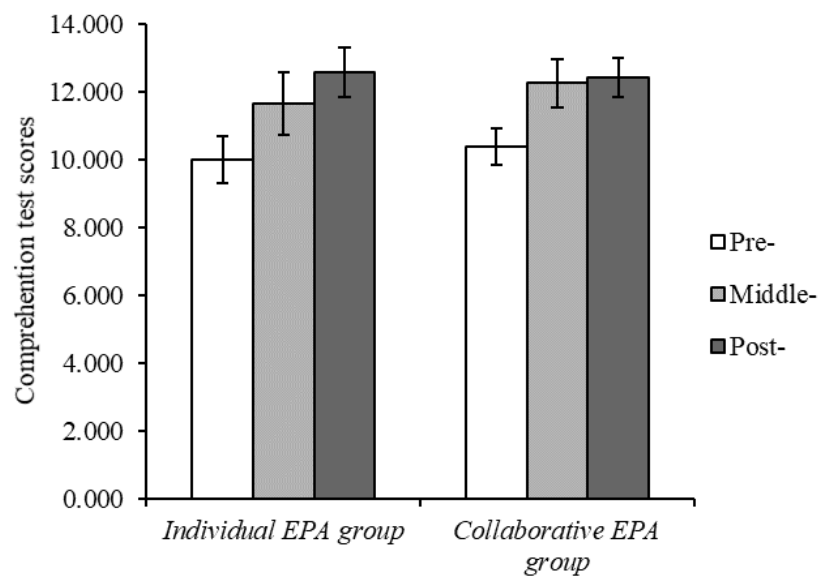

Figure 3. The result of ANOVA

(Error bars indicate standard error) 


\section{CONCLUSION}

The present results suggested that a flipped classroom with EPA of statistical adventure games gradually improves students' understanding. Furthermore, we assumed that collaborative EPA effectively encourage students in knowledge acquisition and construction while watching lecture videos. However, in this study, the reason for which collaborative EPA have a greater effect than individual EPA remains to be identified. We would like to analyze log data of lecture videos and short reflection reports about EPA to consider the ways in which collaborative EPA motivate students to learn statistics.

\section{ACKNOWLEDGEMENT}

This work was supported by JSPS KAKENHI Grant Numbers 18 K02815.

\section{REFERENCES}

Bergmann, J., \& Sams, A. (2014). Flipped Learning: Gateway to Student Engagement. Eugene. OR: International Society for Technology in Education.

Bishop, L. J., \& Verleger, A. M. (2013). The flipped classroom: a survey of the research. 120th ASEE Annual Conference \& Exposition. American Society for Engineering Education, Atlanta.

Greene, A. J., Sandoval, A. M., \& Bråten, I. (2016) Handbook of Epistemic Cognition, Routledge: NY

Kim, K. M., Kim, M. S., Khera, O., \& Getman, J. (2014). The experiences of three flipped classrooms in an urban university: an exploration of design principles. Internet and Higher Education, 22, 37-50.

Oura, H., Ikejiri, R., Nakaya, K., Yamamoto, R., \& Yamauchi, Y. (2018). Preparing Students for Learning Statistics with Adventure Game: Learning Cycle Model of Gaming, Watching, and Practicing. In Kay, J. and Luckin, R. (Eds.) Rethinking Learning in the Digital Age: Making the Learning Sciences Count, 13th International Conference of the Learning Sciences (ICLS) 2018, Volume 3. London, UK: International Society of the Learning Sciences.

Schneider, B. \& Blikstein, P. (2015) Flipping the flipped classroom: a study of the effectiveness of video lectures versus constructivist exploration using tangible user interfaces. IEEE Transactions on Learning Technologies, 9(1): 5-17

Schwartz, D. L. \& Martin, T. (2004). Inventing to prepare for future learning: The hidden efficiency of encouraging original student production in statistics instruction. Cognition and Instruction, 22(2): 129-184

Strayer, F. J. (2012). How learning in an inverted classroom influences cooperation, innovation and task orientation. Learning Environments Research, 15 (2), 171-193. 